\title{
Sara y Agar. Teología y retórica en el Quinientos hispano
}

Para Gema Giner

\author{
José María IÑurritegui Rodriguez*
}

\begin{abstract}
«Esta traducción y declaraciones... no se podian mejor emplear que en servicio de tan esclarecido Reino y República, que con tanta prudencia y quietud ya hace más de setecientos años que se rige y gobierna sin mudanza, ni alteración, ni innovación, ni enfermedad ninguna en la manera de gobierno que notablemente haya estragado la salud perfecta y buen estado de este cuerpo místico de la República, habiendo habido en otros Reinos y diversidad de Repúblicas en todos estos tiempos muchas novedades, motines y alteraciones que demuestran no estar la mixtura de aquellos gobiernos hecha con tanta y tan saludable templanza" 1.

«El pueblo se gobierna mejor con temor y poder justamente administrado que con persuasiones. Por donde la Retórica no sirve ya sino para solas aquellas exhortaciones que en los templos se hacen, con que el pueblo es esforzado a la virtud y verdadera religión»?
\end{abstract}

Pedro Simón Abril, catedrático de retórica de la Universidad de Zaragoza, suscribe ambos comentarios, laude y aforismo ${ }^{3}$. El primer fragmento, atento al gobierno mixto del Reino de Aragón, pertenece a la epístola introductoria de la traducción de Los Ocho Libros de la

UNED

Los Ocho Libros de República del Filósofo Aristoteles traducidos originalmente de lengua Griega en Castellana por Pedro Simón Abril. natural de Alcaraz y Catedrático de Retórica en la Universidad de Zaragoza, y declarados por el mismo con unos breves y provechosos comentarios para todo género de gente y generalmente para la que tiene cargo público. Zaragoza, Lorenzo y Diego Robles, 1984, Epistola Dedicatoria, de donde proceden, mientras no se indique lo contrario. todas las remisiones a este texto.

Pedro SIMON ABRIL, Apuntamientos de cómo se deben reformar las doctrinas y la manera de enseñarlas para reducirlas a su antigua entereza y perfección de que con la malicia del tiempo y con el demasiado deseo de llegar los hombres presto a tomar las insigneas de ellas han caido. Madrid, Pedro Madrigal, 1589 , fol $8 r^{\circ}$ y $v^{\circ}$

Crr., para todo lo relativo a la ficha biográfica del autor y el detallado apunte del conjunto de textos que conforman su obra, Morreale de Castro, M., Pedro Simón Abril. Madrid, 1949. 
República del Filósofo Aristóteles que publica en Zaragoza en 1584. Encuentra acomodo en la intencionada presentación de uno de los depósitos cardinales de las claves y códigos del lenguaje político del republicanismo cívico, de un léxico político ajeno al establecido en el dominio de la teología católica ${ }^{4}$ que habilitaba la posibilidad de compatibilizar y fusionar las libertades aragonesas con la institución monárquica en términos ciertamente constitucionales ${ }^{5}$. El segundo, que sentencia como imperativo derivado del contexto político la irreversible pérdida de operatividad experimentada por la Retórica en la esfera secular del gobierno civil, y reconoce en la predicación, en la instrumentalización de los preceptos retóricos por parte de la oratoria sagrada para la promoción de la virtud y la religión cristiana, el definitivo y exclusivo campo de aplicación para el arte de la persuasión, procede de las páginas de un texto menor dentro de su dilatado itinerario intelectual que ponía en circulación cinco

Cfr., tanto los códigos rectores del lenguaje politico del republicanismo civico como la formulación clásica y reinterpretación humanista de la teoría del gobierno mixto en Pocock, J.G.A., The Machiavellian Moment. Florentine Political Thought and the Atlantic Republican Tradition. Princeton, 1975, págs. 3-80, con el contrapunto crítico, y aqui no compartido, preocupado por reconocer alguno de los elementos definitorios de ese ideal del gobierno mixto en la teorización política de la teologia medieval, y ante todo en la propia Summa de Santo Tomás, de BLYTHE, J.M., Ideal Government and the Mixed Constitution in the Middle Ages. Princeton, 1992, esp. págs. 3959 y 301-307. En relación al papel que desempeña el republicanismo patriótico en el contemporáneo conflicto de los Países Bajos, y más concretamente en la fundamentación y legitimación del acta de abjuración del monarca católico cursada por las Provincias Unidas, ctr., VAN Gelderen, M., The Political Thought of the Dutch Revolt, 1555/1590. Cambridge, 1992, págs. 110-165 y 260266, con el complemento para los términos supraconfesionales de resolución del proceso de Kaplan, B.J., Calvinists and Libertines. Confession and Community in Utrech, 1578-1620. Oxford, 1995, págs. 1-16, el cual reconoce que si en el punto de partida de una rebelión debe ubicarse la decidida resistencia articulada contra la tentativa de confesionalización católica de cuno tridentino promovida por Felipe II, el elemento en verdad configurador de la singular naturaleza tolerante de la República procede y obedece a la notable resistencia que ejerce un determinado grupo, los li. bertinos - al use the term 'Libertine to refer simply to people who rejected ecclesiastic discipline"-, frente a la pretensión calvinista de convertir el territorio en un teocrática "Nueva Israel».

"...de tal manera se templaron las tres especies de gobierno público, que son el Reino, la Aristocrácia, y la que por nombre particular se llama República, que hicieron una que en todos los siglos puede ser dechado de buen gobierno. Porque, cuanto a lo primero, entendiendo que República sin Rey es como cuerpo sin alma, eligieron de su propio cuerpo Rey...y templaron de tal manera esto, y con tanta prudencia, que a la Majestad Real, como es mucha razón, le cometieron el ver y considerar qué leyes convenía hacer para que todos viviesen en paz y quietud, y la aprobación de estas leyes la dieron a los cuatro brazos, que representan todo el pueblon. El argumento ahora puede no sólo entenderse más ajustadamente sino también ubicarse en su específico contexto discursivo merced a los recientes trabajos de Xavier GIL. PUJoL, en especial su introducción a LeONARDO de ARGensola, Información de los sucesos del Reino de Aragón en los años de 1590 y 1591 en que se advierte los yerros de algunos autores. Zaragoza, 1991, y "Aragonese constitutionalism and Habsburg rule: the varying meanings of liberty", KAGAN, R., y PARKER, G. (eds.), Spain, Europe and the Atlantic world. Essays in honour of John Elliot. Cambridge, 1995, págs. 160-187. 
años después en Madrid: los Apuntamientos de cómo se deben reformar las doctrinas.

Enraizada su versión castellana del texto aristotélico en aquel ámbito de la cultura política más afectado por la reconquista de lo clásico y la experiencia que madura la cultura europea a través del realismo de la filología, no parecía gratuito ni casual que la Política viniese dirigida al llustrísimo Señor el Reino de Aragón, y en su nombre al muy llustre Señor sus Diputados. En realidad, tanto la propia edición de unos Libros de República - en los que la lectura de Simón Abril reconocia la intención "de enseñar a los hombres de qué manera han de vivir en compañía y pretender un bien común de todos que llamamos República» ${ }^{6}$-, como el consustancial enriquecimiento y renovación del utillaje conceptual en la fundamentación del discurso político que implica la empresa, abierta y confesadamente se acometía para ilustrar a las Cortes "la gran provisión de sus antepasados en el fundar y dar asiento a las cosas de la República». En el curso de acción que activa la redacción de los Apuntamientos — «la calentura ética que va consumiendo la virtud a la doctrina y transformándola poco a poco en puro barbarismo»- resonaban con más nitidez sin embargo los ecos de la turbulenta experiencia del humanismo en las latitudes de la Monarquía Católica ? Otro dictado aristotélico, en este caso con la Ética como referente - "que a la suprema majestad toca el determinar qué doctrinas se han de enseñar en la República y el cómo y porque orden"-, reclamaba entonces, por método y contenido, colocarlos alternativamente bajo la protección de Felipe II, pues «si por merced particular, que Dios ha querido hacernos, tiene la suprema potestad temporal en la mayor parte del mundo, los que desean ver las buenas letras quitadas de su barbarismo en que hoy están puestas, y reducidas a su antigua luz y perfección para mayor bien de la República, de necesidad han de acudir a V.M. a darle aviso de esto, como a quien sólo en la tierra tiene poder y autoridad para poner remedio a ello" ${ }^{8}$.

Aquí, en verdad, interesan más unos Apuntamientos que una Política. O mejor dicho, interesa primeramente rastrear el sentido último de la irrevocable reclusión de la Retórica en las fronteras eclesiales que un autor,

\footnotetext{
Pedro Simon Abril, Libros de República..., fol $1 \mathrm{v}^{\circ}$, "Declaración de todo el proceso de la moral filosofía del Filósofo Aristóteles, con que el que de ella quiera sacar algún fruto, que le quede, vaya bien instruido e informado en el proceso de la obra".

Cfr., Pedro Simon Abril. Apuntamientos..., fol. $2 v^{\circ}$, y para las coordenadas en las que parecia anclarse la afirmación, Rıco, F., Nebrija frente a los barbaros. Salamanca, 1978

Pedro Simón Abril., Apuntamientos..., fol. $2 \mathrm{r}^{\circ}$.
} 
instruido en los supuestos de fondo del aristotelismo político, paradójicamente reconoce y sentencia en las páginas de una obra en cuya preocupación cardinal, la formación de las futuras élites rectoras de la República, subyacia la centralidad conferida a la Bildung por aquella paideia concebida en tiempo renacentista bajo titulación de studia humanitatis ${ }^{9}$. Por ello si acotar el singular perfil de unos textos ya nos proporciona el primer e individualizado contexto para la lectura de unos fragmentos, el cruce de sus registros evidencia sugerentes y significativas distancias a su vez referenciales y contextualizadoras a la hora de reconocer la trascendencia que reviste en la concreción de un modelo cultural la plena transferencia, desde las coordenadas del saeculum a las de una Ecclesia, del potencial recurso a los mecanismos del arte de generar convicción.

En el meridiano de un tiempo de las confesiones, que desconoce la separación entre religión y política, el ámbito de despliegue asignado por Simón Abril a la Retórica evidentemente no resultaba ser un destino de orden menor ${ }^{10}$. La misma fractura de la Christianitas que activa y precipita una cerrada confrontación confesional redimensionaba -en términos bien sustantivos de ortodoxia y magisterio- el inicial encuentro filológico entre humanismo y escolástica, trasladando la Retórica a las coordenadas de la definición y defensa de un credo, una vera religio, y de unas cerradas concepciones eclesiales ${ }^{11}$. Dadas las condiciones en que se venía desenvolviendo el debate político finisecular tampoco resultaba además marginal, ni mucho menos, el cometido que por este cauce ahora le venía impuesto: la promoción de la virtud. Con la crisis del iusnaturalismo cristiano - que posee

«Es cosa en que le va gran interés a la República, y particularmente al servicio de V.M. para poder tener abundancia de ministros bien enseñados, para que sirvan a V.M. en este ministerio del gobierno, como gentes que se ha dispuesto para ello". Pedro Simon ABRil., Apuntamientos..., fol. $3 r^{\circ}$

La radiografía del mismo en su vertiente católica es ahora posible merced al operativo informe temático reunido en O'MaLley, J.W. (ed.), Catholicism in Early Modern History: A Guide to research. San Luis, 1988.

Cfr., la pormenorizada reconstrucción de las etapas y lineas de fuerza del debate entre humanismo y escolastica recientemente propuesta por Erika Rummel. The Humanist-Scholastic Debate in the Renaissance and Reformation. Harvard, 1995 (o en versión abreviada, "Et cum theologo bella poeta gerit. The Conflict between Humanist and Scholastics Revisited". Sixteenth Century Journal, XXIII/4 (1992), págs. 713-726), con el complemento relativo a la vertiente y valencia confesional implementada a la retórica tras la Reforma de O'MALLEY, J.W., "Content and Rhetorical Forms in Sixteenth-Century Treatises on Preaching", en MURPHY, J.J. (ed.), Renaissance Eloquence. Studies in the Theorye and Practice of Renaissance Rhetoric. Berkeley, 1983, págs. 238-252, Shuger, D., "Sacred Rhetoric in the Renaissance", en PLETT, H.F., Renaissance Rhetorik. Berlín, 1993, págs. 121-143, y MEERHOFF, K., "The significance of Philip Melanchton's Rhetoric in the Renaissance", en MACK, P., Renaissance Rhetoric. Londres, 1994, págs. 46-62. 
un escenario, el ámbito francés de las guerras de religión en que se niega la existencia de un vínculo unívoco entre canon ético objetivo y disposiciones normativas contingentes, y también una motivación, la novedosa percepción del tiempo generada por la fragmentación de la Cristiandad-como telón de fondo, el divergente entendimiento e interiorización de la virtud incardinaba y cifraba la polémica nodal del último Quinientos: la relativa a la permanencia de las repúblicas en el tiempo y los medios que lo garantizan ${ }^{12}$. Sujetos a debate los elementos vertebradores del ordenamiento europeo, la religión y la virtud, emitir en el ámbito de influencia monárquico un escrutinio y diagnóstico sobre la retórica y su operatividad entrañaba por tanto a la altura de 1589 evidentes implicaciones, acentuadas indudablemente por el singular cierre en clave tomista conferido desde Salamanca a la experiencia del humanismo por la teologizada matriz cultural hispana ${ }^{13}$.

Afirmar que en la fecha la reconocida valencia activa de la Retórica para docere y movere sólo parecía mantener plena vigencia en el delimitado universo del gobierno eclesiástico ${ }^{14}$ significaba ya primeramente en este sentido reconducir el interés hacia el fundamental proceso de articulación verbal de la fe. La mera constatación venía así a consolidar su empleo en la vertebración del discurso cristiano, es decir, en la declaración y proclamación desde el púlpito de las creencias y prácticas aparejadas al dictado de un credo por el que se reafirma verbalmente la esencia y contenidos de una fe y se concreta la condición militante del individuo en una comunidad eclesial ${ }^{15}$. Justificación para el componente retórico del discurso religioso además no se requería. Con una retórica bíblica ${ }^{15}$ y una

12 Cfr., como encuadre para sus lineas maestras, TuCK, R., Philosophy and government, 1572-1651. Cambridge, 1993, págs. 31-153, y para la crisis del iusnaturalismo católico. BATTISTA A.M., Alle origini del pensiero politico libertino. Montaigne e Charron. Milán, 1989, págs. 133-171

$13 \mathrm{Cfr}$. el balance acuñado por LAWRANCE, J., "Humanism in the Iberian Peninsula", en Goodman, A., y Mackay, A., (eds.). The Impact of Humanism on Western Europe. Londres, 1990, págs. 220-258, así como la introducción de Anthony PAGDEN a Francisco DE VitoriA, Political Writings -Cambridge, 1991- o el reciente y novedoso escrutinio de una segunda escolástica acometido por FERrADo, D., Itinerari del volontarismo: teologia e politica al tempo di Luis de León Milán, 1995.

14. E incluso aquí Simón Abril reconocia un camino por recorrer y una tendencia que rectificar: "Y aún en esto los predicadores siguen más sus propias invenciones (lo que no deberian) que el artificio de bien persuadir, como aquellos santos antiguos lo hicieron". Pedro Simon ABril, Apuntamientos..., fol. $8 \mathrm{~V}^{\circ}$

15. Cfr., O'MAlley, J.W., Praise and Blame in Renaissance Rome: Rhetoric, Doctrine and Reform in the Sacred Orators of Papal Court, ca. 1450-1521, Durham, 1979, pags. 72-75, y MCGINNESS, F.J., "Preaching Ideals and Practice in Counter-Reformation Rome". Sixteenth Century Journal, 11 (1980), págs. 117-123.

16 Cfr., Poland, L., "The Bible and the Rhetorical Sublime», en WafNer, M. (ed.), The Bible as Rethoric: Studies in Biblical Persuasion an Credibility. Nueva York, 1990, esp. págs. 35-37. 
retórica patrística ${ }^{17}$ como tradicional soporte en la exposición del dogma católico, testimonio del Verbo encarnado donde el mismo lenguaje ya se concibe como fenómeno teológico, la propia finalidad de esta modalidad de apostolado, persuadere ad populum, fortalecer la convergencia entre persuasión, siempre con la virtud como sujeto ${ }^{18}$, y disciplina confesional ${ }^{19}$, enmarcaba y encuadraba con relativa naturalidad la sentencia. Como levanta acta poco después Pedro de Ribadeneyra -en su edición castellana del Ecclesiastes sive de ratione concionandi instructio de Francisco de Borja- para una cultura católica, preocupada explícitamente en el tiempo por la “reformación de la república» que genera la predicación, no se trataba de un dictado excéntrico el emitido por Simón Abril, pues resultaba ser una convicción plenamente asentada que «el fin y blanco a que los predicadores deben mirar no es solamente el declarar las verdades y misterios de nuestra santa Religión, ni el deleitar y agradar a los oyentes, y mucho menos el vano aplauso de la gente popular, sino el trocar los corazones e inflamar las voluntades de todo el auditorio y persuadirle de que de mano a los vicios y se abrace con la virtud» 20 .

Ahora bien, esa referencia a la virtud, inherente a la reflexión sobre la modulación discursiva que venía trazándose desde la tradición retórica hispano-católica ${ }^{21}$, no era semántica ni conceptualmente neutra. El propio Ribadeneyra, en una intervención posterior, el De Instituto Societatis lesu, rendía buena cuenta al respecto. Fijaba alli, en principio, unos precisos

Cfr., Mufpryy, J.J., La Retórica en la Edad Media. Historia de la teoria de la retorica desde San Agustin hasta el Renacimiento. México, 1986. págs. 56 y ss.

Cfr., Trinkaus, CH., "The Question of Truth in Renaissance Rhetoric and Antropology", en Murphy, J.J. Renaissance Eloquence..., págs. 207-220. esp. pág. 214, y como exponente máximo de este entendimiento e interiorización del fin último de la predicación. OMALLY. J.O., The First Jesuits. Harvard, 1993, págs. 91-104, quien en otra intervención - "Luther the Preacher", en Dünnhaupt, G., The Martin Luther Quincentennial. Detroit, 1985, págs. 3-16- se ocupa además de puntualizar la singularidad frente al universo luterano implicita en el razonamiento.

Para el significado e implicaciones de la dinámica cfr., la puesta al dia en la materia que Wolfgang REINHARD y Heinz SCHILl ING realizan en PRODI, P. (ed.), Disciplina dellanima. disciplina del corpo e disciplina della società tra medioevo ed età moderna. Bolonia, 1994, págs. 121-123 y 125-160 respectivamente.

Cfr. la presentación al lector del Tratado breve del Padre Francisco de Borja para los predicadores del Santo Evangelio, en Pedro de RIBADENEYRA, Vida del Padre Francisco de Borja que fue Duque de Gandia y después Religioso y III General de la Compañia de Jesús, Madrid. Pedro Madrigal, 1592.

Cuyo perfil viene fijandose desde la historiografía filológica y literaria. Cfr., por ejemplo, Lopez Grigera, M.L., La retórica en la España del Siglo de Oro. Salamanca, 1994 -que reconoce en la figura y obra de Pedro Simón Abril el simbolo del ciceronianismo hispano (pág. 51)-Rico Verdú, J., La Retórica española de los siglos XVI y XVII. Madrid, 1973, y MARTI. A.. La preceptiva retórica española en el Siglo de Oro. Madrid, 1972. 
cauces de interiorización y entendimiento para las nociones fundamentales en las que arraiga ese lenguaje: "la caridad y las otras virtudes infusas son la salud del alma y en ellas consiste la perfección cristiana". $Y$ así retrataba todo un sistema mental y una concepción del mundo en función de cuyos supuestos de fondo, el Amor Dei y la Caridad, se articulaban las formas expresivas que confieren y salvaguardan la identidad de una cosmovisión cerradamente confesional: «los actos interiores de las virtudes morales se enderezan a la pureza del alma y a la victoria de las propias pasiones, y todas las virtudes morales y teologales tienen por fin el amor de Dios y del prójimo» 22 .

Entroncar con la antropología católica subyacente en ese discurso anclado en un lenguaje de providencia, gracia y virtud infusa, bien podia suponer en el preciso caso de Simón Abril la necesidad, al menos formal y discursiva, de abdicar y repudiar otros entendimientos antitéticos de la virtud que no le resultaban extraños, comenzando por el aparejado al vivere civile que reconocía en sus declaraciones a los Libros de República: "Declara en el capítulo presente [III del Libro III] la propia virtud del Ciudadano en cuanto Ciudadano, porque en cuanto hombre ya la declaró en las Éticas. Muestra por muy palpables comparaciones ser en alguna manera diferente la virtud del Ciudadano en cuanto tal y la del mismo en cuanto hombre. Declara ser las virtudes de un buen Ciudadano el tener por principal la conservación del bien común, la prudencia y la experiencia en negocios y autoridad" 23. Si como cifraba con nitidez Fray Luis de Granada -en su Ecclesiasticae rhetoricae sive ratione concionandi libri sex ${ }^{24}$ - desde posiciones de implicación católica se atendia y abrazaba la retórica para responder y combatir a unos heréticos con las mismas armas que venían empleando en el despliegue de su ofensiva contra la iglesia católico-romana, o dando un paso más, si la retórica adquiria carta de naturaleza en una cultura con la reforma moral y la colaboración con la gracia ubicadas en el punto de mira, con la teologizada convicción de que sólo por medio de la gracia y en comunión con una Iglesia era posible alcanzar una vida virtuosa plena, aquella concepción propiamente aristotélica de un habito sujeto a adiestramiento que en el campo ético se denomina virtus por supuesto no tenía cabida alguna. Así las cosas, identificada

Pedro ly RIBAdenfra, Tratado en el qual se da razón del Instituto de la Religión de la Compania de Jesús. Madrid, Colegio de la Compañia de Jesús, 1605, fol. $2 v^{\circ}$ y págs. 23-24.

Pedro Simon Abril, Libros de Republica... fols. $63 v^{\prime \prime}$ y $64 r^{\prime \prime}$

Luis de Granada, Ecclesiasticae rhetoricae sive ratione concionandi libri sex. Venecia, $\mathrm{F}$ Zilettus, 1578 , págs. 10-11 
la educación retórica con la predicación, la sapientia con los arcana de una Ecclesia, y reconocida confesionalmente como finalidad exclusiva y excluyente de la elocuencia la defensa de la Religión y de la Respublica Christiana, con la consiguiente recalificación del binómio ratio/oratio, la perenne tensión entre vida activa y vida contemplativa se neutralizaba entonces unidireccionalmente con el reclamo de una contemplación en acción y de su virtud consustancial, eminentemente teologal ${ }^{25}$.

El componente de exclusividad eclesiástica dictaminado para la retórica encerraba correlativamente por este cauce una segunda implicación al respecto en absoluto intrascendente. Suponía vaciar y aniquilar el contenido político que le había sido consustancial en otros tiempos y en otros contextos. Si en la estela del redescubrimiento de los textos clásicos de la Antigüedad la fusión de inequívoco sabor humanista entre eloquentia y sapientia habia podido soportar en ciertas latitudes el reclamo de una vita activa y un vivere civile, esta no parecía tener cabida en el seno de una Monarquía Católica de compleja conformación territorial y cerrada definición confesional, donde tan sólo se reconocía posibilidad y espacio para una vida contemplativa ${ }^{26}$. Con su apunte, Simón Abril en realidad estaba así acotándo, aunque indirectamente, el perfil e identidad de la Monarquia. Insinuaba el entendimiento teologizado de la política y lo político que la singulariza, y con ello las derivaciones prácticas de la vigencia en el ámbito hispano de un orden de principios indisponibles - dados por una tradición religiosa y materializados por la teología-, de un universo mental de matriz castellana y proyección europea fundado sobre la prioridad de una confesión y la ausencia de una vida política activa ${ }^{27}$.

Divergencias bien sustantivas adquirían cuerpo en este sentido con respecto a otras matrices culturales. Ya lo eran de raiz. Si la elocuencia del humanismo aspira a combinar la funciones de la retórica y la filosofía,

\footnotetext{
25 Cfr., por el papel en cuanto fuerza motriz que cabe y debe reconocersele a la Compañia de Jesús tanto en la concepción del giro como en su concreción. O'MALLEY. J.W., The First Jesuits.... págs. 69-104 y 244-272. Para adquirir una perspectiva de las implicaciones, cfr., SEIGEL. J.E., Rhetoric and Philosophy in Renaissance Humanism: The Union of Eloquence and Wisdom. Petrarch to Valla. Princeton, 1968, págs. 3-98.

${ }_{2 f_{j}}$ Cfr., para las reconocidas divergencias inherentes a tan antigua tensión, Pocock, J.G.A., "The Ideal of Citizenship Since Classical Times", Queen's Quaterly, 99/1 (1992), págs. 33-55.

Cfr., Fefnandez Albaladejo, P., "Católicos antes que ciudadanos: Gestación de una 'Politica Española' en los comienzos de la Edad Moderna", Il Ciclo de Historia Urbana, Santander. 1996, en prensa, VIEJO, J., "El sueño de Nabuconodosor. Religión y politica en la monarquia católica a mediados del siglo XVII", Revista de Estudios Políticos, 84 (1994), págs. 145-163, e Inuraitegui, J.M., La Gracia y la República. El lenguaje politico de las teología católica y el 'Principe Cristiano'de Pedro de Ribadeneyra. Tesis Doctoral, UAM, Madrid, 1995.
} 
el poder persuasivo de una y el rigor doctrinal de la otra, aquí la fusión y sumisión se trazaba respecto al registro teológico. Pero sobre todo la disparidad lo era de cultura política. Subsumida la idea clásica del vir humanus en la idea bíblica del hombre como imago Dei, la retórica incardina durante el Renacimiento unos studia humanitatis y resulta la pieza cardinal del discurso en cuanto indispensable llave de acceso para la captura de la elocuencia clásica ${ }^{28}$. Reemplaza a la lógica como componente nuclear del diseño curricular, o a la propia retórica de tradición y herencia medieval, diluyendo la naturaleza pragmática del interés retórico precedente ${ }^{29}$. Ahora bien, aquel reconocimiento y aquella rehabilitación lo que permitía principalmente era articular a un civic humanism su discurso político republicano ajeno al entramado conceptual escolástico ${ }^{30}$. O mejor dicho, la explotación inmediata y asi relativamente encubierta de un aristotelismo ajeno al filtro y refundición acometidos en la Suma Teológica de Santo Tomás ${ }^{31}$. Que esa línea del discurso político resultase ser según sabemos la abrazada en la intervención de Simón Abril de 1584, al traducir unos Libros de República, insinúa precisamente, en una de sus vertientes, toda la dimensión y entidad de la precisión sobre la Retórica que nos ocupa, concebida

\footnotetext{
Cfr., Nauert, Ch.G., Humanism and the Culture of Renaissance Europe. Cambridge, 1995, págs. 10 y ss.

En relación al sentido y carácter de la adaptación medieval de la teoria retórica clásica y la arraigada convicción sobre las posibilidades que encierra su empleo en ámbitos y contextos radicalmente dispares de los originales, la cual activa y subyace en la concreción de un síntesis no menos homogénea que intencionada a partir del cruce y fusión de diferentes fragmentos, cfr., Grafton, A. y Jardine, L., From Humanism to the Humanitates: Education and the Liberal Arts in Fifteenth and Sixteenth Century Europe. Harvard, 1986, págs. xi//xvi. Para las implicaciones del giro humanista en la aproximación y labor textual - «that any classical text was not just the product of a single intellect but a subordinate part of an organic cultural and historical whole"- cfr., Grafton, A., Defenders of the Text: The Traditions of Scholarship in an Age of Science. 1450/1800. Cambridge, 1991, pág. 30 y como pormenorizado recorrido por la historia de la retórica renacentista, Monfasani, J., "Humanism and Rethoric", en Rabil, A. (ed.), Renaissance Humanism: Foundations, Forms and Legacy. Filadelfia, vol. 3, 1988, págs. 171-235, atento además a las críticas de la estructura teórica de la retórica clásica y las reivindicaciones en favor del retorno a la comprensión medieval de sus propósitos y contenidos que comparecen en la propia órbita del humanismo, o al debate entre quienes propugnan la asimilación plena del arte clásico de la retórica y aquellos que pretenden adaptarlo a las prácticas y valores contemporáneos.

30 Cfr. BARON, H. «Leonardo Bruni: 'Prolessional Rhetorician' or 'Civic Humanis'?". Past and Present, 34 (1967), págs. 21-27, y RaBll, A., "The Significance of 'Civic Humanism'in the Interpretation of the Italian Renaissance", en RaBlL, A.., (ed.), Op. cit., vol. 1, págs. 141-174.

Cfr., el recorrido panorámico de Skinner, Q., "Political Philosophy», en SCMMitt, CH.B y Skinner, Q., (eds.). The Cambridge History of Renaissance Philosophy. Cambridge, 1988, págs. 389-452, el análisis de la gestación y concreción histórica de un alanguage of politics from the traditions of political virtue, civil law and Aristotelianism" en VIROLI, M., From Politics to Reason of State. Cambridge, 1992, págs. 71-177, y como referencia básica, fundamental e indispensable para el reconocimiento de dos modelos de discurso político divergentes, el uno basado en la ley y el otro en la virtud republicana, Pocock, J G.A., Machiavellian Moment... Parte I.
} 
ya en base a la percepción de la realidad política en clave teológica y en términos de dependencia con respecto a los dictados dogmáticos de una religión imperante en la Monarquía Católica.

Cuestiones de cultura política y cuestiones de índole cerradamente confesional se entrecruzaban por tanto en esa sentencia, en absoluto inocua, referida a la retórica que encontraba acomodo en las páginas de unos Apuntamientos. La misma sin embargo no estaba exenta de matices que tampoco conviene olvidar. Algo más precisaba Simón Abril en su exposición: "Por esto convendría que pues ya ni en los senados ni en las audiencias no hay materias para hacer semejantes oraciones, se tradujese del Latín y del Griego las mejores oraciones de Tulio y de Demóstenes, y los sermones de aquellos grandes predicadores San Basilio, San Crisóstomo, San Cirilo, San León, por personas que supiesen representar sus virtudes y estilo en lengua popular, para que estos sirviesen de exemplo y experiencia de como debe usarse y ejercitarse la Retórica» ${ }^{32}$. Recluir la retórica en la esfera eclesiástica no suponía consecuentemente renunciar a unos clásicos. Conocer y familiarizarse con la elocuencia y la capacidad expresiva de autores paganos como Cicerón quedaba prescrito junto a la recuperación de los modelos retóricos cristianos como referentes canónicos en la adecuada exposición de la fe. Y, denegada una vida política, su existencia, deslizar la posibilidad de soportar la declaración dogmática en la retórica clásica, con las evidentes connotaciones de índole teológico que ello entraña, tenía una intención y un sentido que pronto se confiesan y descubren.

La fikisofía subyacente en el reclamo cursado por un catedrático de retórica plenamente comprometido con la prospección del mundo clásico guardaba además en principio cierta coherencia con la dinámica dominante contemporáneamente en el corazón del universo católico-romano. La intencionada instrumentalización y aplicación en la oratoria sagrada de los principios de la retórica clásica que se activa a finales del Quinientos desde los círculos papales venía constituyendo al respecto uno de los principales cauces de reconstrucción y rearticulación de una cultura enucleada por el recte sentire, por la ortodoxia confesional. La recuperación de una temática y unos ideales inequívocamente humanistas para su premeditada reorientación hacia la esfera eclesiástica, la apropiación selectiva por parte de la iglesia católico-romana de una tradición cardinal del humanismo renacentista, el revival de los modelos clásicos de oratoria, como

Pedro SIMON ABril, Apuntamientos..., fol. $9 \mathrm{r}^{\mathrm{s}}$ 
herramienta fundamental en la formación del cristiano y en la propagación de la fe, demostraba así en la fecha un acusado potencial de signo confesional en la neutralización y respuesta de alternativas opciones eclesiológicas y político-morales al menos equiparable al implícito en la concreción de una renovada historia eclesiástica, en la gestación de un corpus de literatura antiprotestante e incluso en la culminación teórica de una teologia escolástica ${ }^{33}$.

Semejante regeneración de la oratoria sagrada en defensa de la Respublica Christiana no parecia ser sin embargo el principal referente con que operaba Simón Abril en su composición, ni la principal referencia a la hora de emitir su propuesta. Iniciado el recorrido de la obra con el escrutinio de los errores curriculares que lastraban el trabajo pedagógico en los específicos dominios de la gramática y la lógica, tras el apartado consagrado a la retórica comparecía el pormenorizado análisis que Simón Abril realizaba de las retos que habian de afrontarse en la enseñanza de las matemáticas, la filosofía natural, la filosofía moral, la medicina y el derecho, para concluir significativamente y de manera en absoluto casual con la teología. Nítido retrato de la configuración piramidal del organigrama de una cultura y de las prioridades y primacías así consagradas, tras fijar un relativo distanciamiento con respecto al modus operandi escolástico, acorde con las directrices rectoras de su itinerario intelectual, — «no es $\mathrm{mi}$ intención, ni tal Dios permita, dar en el disparate en que han dado los herejes en nuestros tiempos, reprendiéndo así en común toda la Teología que vulgarmente llaman Escolástica»-, el autor retomaba en las coordenadas de la materia teológica aquel vínculo entre predicación y elocuencia insinuado y aludido con ocasión del repaso a la materia retórica; es decir, el nexo que venía trazándose entre retórica, virtud y religión, y si se quie-

Cfr, el excelente estudio de McGinness, F.J., Right Thinking and Sacred Oratory in Counter-Reformation Rome. Princeton, 1995, esp. págs. 9-61, y alguna de sus intervenciones anteriores, en especial, "The Rhetoric of Praise and the New Rome of the Counter Reformation", en Ramsey, P.A. (ed.), Rome in the Renaissance: The City and the Myth. Nueva York, 1982, paigs. 355-370, lecturas ambas que bien pueden complementarse por un lado con FuMarol LI, M., L'Âge de l'éloquence. Rhétorique et res literaria de la Renaissance au seuil de l'époque classique. Ginebra, 1984, págs. 116-230 -y su llamada de atención (pág. 138) sobre cómo "directement sous son influence [del Cardenal Borromeo], ou indirectement sous l'effet de l'heureuse conclusion du Concile s'ouvrit en Italie et en Espagne un veritable 'atelier' de réthorique, plus prolifique qu'aucune école de sophistes antiques ou qu'aucune Académie humaniste" - y por otro, con las investigaciones más propiamente centradas en las tradiciones retóricas, políticas y teológicas operativas en el renacimiento romano, ante todo, D'AMICo, J.F., Renaissance Humanism in Papal Rome. Baltimore, 1983, y O'MALLEY, J.W., "The Feast of Thomas Aquinas in Renaissance Rome: A Neglected Document and Its Import". Rivista di Storia della Chiesa in Italia, 35 (1981), págs $1-2.7$ 
re, dando un paso más, la justificación del uso y conocimiento de la retórica grecolatina - junto a la matricial retórica bíblica y patrística - al servicio de la articulación del pensamiento cristiano y de la propagación de la fe y el dogma católico:

"Y pues el predicar es una de las mayores obras de nuestra sagrada religión, y de que más Dios se sirve y más el pueblo christiano se aprovecha, y este oficio importa mucho hacerse bien pues del hacerlo bien o mal tanta atraviesa hay de daño y de provecho, y el bien predicar, demás de que requiere buena naturaleza, consiste también en cierta manera de doctrina y ejercicio, error de hombres es no fundar una lección de como se ha de predicar bien dando sus reglas y doctrinas para ello y leyendo para ejemplo los sermones de San Basilio, San Cirilo, San Crisóstomo, San Agustín, San Cipriano, San León Papa y otros muchos que nos dejaron escritos sus sermones, y particularmente las epístolas de San Pablo, que están llenas de elocuencia cristiana, aunque para lo que toca al estilo y figuras de oración también es útil la lección de los buenos oradores Griegos y Latinos" ${ }^{34}$.

La resolución unidireccional de la dualidad aristotélica entre pensamiento y elocución, la neutralización de la perenne oposición entre res y verba quedaba así insinuada implementándose a los modelos de expresión del arsenal retórico clásico la sapientia y elocuentia contenida en los arcana de la religión cristiana, comenzando por unas Escrituras. El ideal ciceroniano de una teología humanista, o mejor dicho, de una teología retórica, tan arraigado entre quienes conforman a comienzos del Quinientos aquello que se ha venido denominando como humanismo cristiano, parecía de nuevo asi reivindicado ${ }^{35}$. El esfuerzo por conjugar la retórica clásica y la sagrada para solucionar los problemas de la oratoria confesional, que tanto habian ocupado y preocupado en ámbito hispano a los autores interesados en establecer un compromiso entre la retórica y el dogma cristiano, la unión entre la verdad y la elocuencia ${ }^{36}$, encontraba un convergente cauce de expresión en las páginas que Simón Abril dedicaba a la reformulación metodológica y estratégica de la praxis teológica. Aquí se anudaba el texto y trasparentaba el autor el curso de acción específico sobre el que procura incidir con su composición. La recuperación de quie-

Pedro Simon Abril, Apuntamientos..., fol. 22vo

Cfr., O'MALlEY, J.O., Praise and Blame..., pág. 124, y Rico, F., El Sueño del Humanismo Madrid, 1993, págs. 100-125.

36 Cfr., Galan Vioque, G., "Humanistic Influences in the Spanish Rhetorician Alfonso Garcia Matamoros (1572): A study of De ratione dicendi libri duo (Alcala, 1548)", Rhetorica (1994), págs. 155-171, O'MALLEy, J.W., "Content and Rethorical Forms in Sixteenth-Century Treatises on Preaching", en MURPHY, J.J. (ed.), Renaissance Eloquence..., págs. 238-252, y FUMAROLLI, M., L'Âge de l'éloquence..., págs. 116-148. 
nes como Agustín o Crisóstomo ejemplifican el empleo y aplicación de la retórica clásica en la defensa de la fe y la propagación del sentido último del Evangelio por ello cuadraba perfectamente con el controlado repudio del método escolástico apuntado por Simón Abril. Reconducir la atención hacia "los libros sagrados, los decretos de los santos Concilios, las doctrinas de los Santos Antiguos y las historias de las cosas de la Iglesia", como cauce de regeneración de la recta formación teológica, tenía entonces todo su sentido en las coordenadas de una propuesta enraizada en el plano formativo del cristiano. Las oscuras cuestiones escolásticas, los complejos silogismos y las áridas conclusiones entrecruzadas con ánimo y vocación de irrefutable demostración resultaban desde ese punto de vista innecesarias, cuando no perjudiciales y contraproducentes. Partiendo de la gramática, se propugnaba desde la retórica otra teología. Era por tanto otra vía, cuando no la única via humanisticamente reconocida, para alcanzar un completo sometimiento y obediencia a la Iglesia como garante de una tradición y de un dogma ${ }^{37}$.

Buscar una filiación genética para legitimar en su conjunto el espiritu crítico de los Apuntamientos no dejaba de tener por ello un cierto sentido dado que la reclamación cursada, en última instancia, ni tan siquiera propugnaba culminar con la teologia una ratio studiorum que partiese de los studia humanitatis, llegar jesuíticamente a la Suma de Santo Tomás tras familiarizarse con Cicerón y Quintiliano ${ }^{38}$, manteniendo ambos desarrollos como vias paralelas, aunque en principio, y por la arquitectura del texto, así pudiera pensarse. Esa operación y justificación sin embargo podía encerrar ciertas sorpresas, paradojas al fin y al cabo decisivas para ubicarnos ante la suerte que le podía esperar a la empresa: "De las muchas faltas que hay en el enseñar las doctrinas escribieron discretamente Luis Vives, en un libro que particularmente escribió de esta materia, y fray

Lo cual ya podía demostrarse incluso en primera persona al proceder el autor at cierre de su texto: "Pero con todo esto conociendo que soy hombre, y por la misma razón sujeto a error, digo a V.M. que todo esto lo he dicho y lo digo debajo de la corrección de la Santa Iglesia Católica Romana a quien me sujeto; y si algo he dicho que ella no lo tenga por bueno desde ahora lo doy por no dicho y por retratado; y lo que ella determinara tengo por verdad, y lo contrario por error, $y$ asi lo afirmo». Pedro SIMON ABrIL, Apuntamientos ..., tol. $23 r^{\circ}$

Para todo lo relativo a la Institución jesuitica, Cfr., CESAREO, F.C., "Quest for Identity: The Ideals of Jesuit Education in the Sixteenth Century", $\mathrm{CHAPEL}, \mathrm{CH}$. (ed.). The Jesuit Tradition in Education and Missions. A 450-Year perspective. Londres-Toronto, 1993, págs. 17-33, del mismo, "The Collegium Germanicum and the Ignatius Vision of Education", Sixteenth Century Journal, XXIV/4 (1993), págs. 829-841, Ganss, G.E., St. Ignatius'ldea of University. A Study in the History of Catholic Education. Milwaukee, 1954, y por último, O'MALLEY, J.W., "Renaissance Humanism and the Religious Culture of the First Jesuits", Heytrop Journal, 31 (1990), págs. 471-478. 
Melchor Cano, obispo de Canarias, en los libros que escribió de los lugares teológicos". Los registros reunidos desde luego no eran univocos. Más bien simbolizaban discursos alternativos. Aunque la codificación de los resortes doctrinales de la ciencia sacra rememorase formalmente la sistematización humanística de los mimbres para la invención retórica, situar el eje de gravedad en la Gramática o hacerlo en la Teología no era una simple cuestión de matices. El De Disciplinis de Luis Vives, cuya impronta ya subyace en el título de Simón Abril, exploraba la trayectoria, contenido y alcance de las artes ad humanitatem. No así el De Locis Theologicis de Melchor Cano, atento a la fundamentación del razonamiento teológico. Ubicar a la res literaria como núcleo de una cultura difería radicalmente de la conquista de nuevas provincias del saber y su acomodación orgánica en el edificio teológico. $Y$ además la compatibilidad ya podía denegarla incluso alguno de los propios protagonistas, pues al dotar de una sólida estructura metodológica a la tarea teológica Cano encontraba espacio para la imputación contra Vives ${ }^{39}$.

Distancia, pues, había, pero Simón Abril parecía obligado a omitirla. $Y$ no sólo de palabra. Alguno de los párrafos en los que la filosofía de los Apuntamientos emerge con más claridad bien podían pertenecer a las páginas de Vives: «Tercer error común en el enseñar las ciencias es el desordenado deseo que tienen los que aprenden de llegar de presto a tomar las insigneas de la doctrina, que vulgarmente llaman grados, a que tienen hoy más ojo los hombres por sus particulares ambiciones y codicias que a salir con la empresa de la verdadera doctrina. Porque de aquí nace el desear ser enseñados los hombres por compendios, sumas o sumarios, y no tener paciencia para leer lo que los varones antiguos escribieron de cada una de ellas largamente, que es lo que va destruyendo y haciendo poner en olvido la lección de los antiguos escritores». Pero en otros fragmentos, especialmente aquellos en los que la impronta de la teologizada matriz cultural de la monarquía es más evidente, la sombra de Cano se hacia bien presente: "La Sagrada Teologia, en cuanto es de su parte no tiene error ninguno, antes ella es la luz y la guía de todas nuestras obras y el peso con que se pesa la verdad, y la Sara, que es la señora a quien a de estar sujeta la criada Agar, que significa las demás ciencias" ${ }^{40}$.

Que Simón Abril, por la propia naturaleza de su tentativa, miraba más a Luis Vives que a Melchor Cano, ahora ya nos puede resultar evidente.

\footnotetext{
Melchor Cano, De locis theologicis libri XII. Salamanca, Matias Gastius, 1563 -que cito por la edición de Padua de 1714- lib. X, cap. 9, págs. 269-270.

Pedro Simon Abril., Op. cit., fols. $4 v^{\circ}$ y $20 v^{\circ}$ respectivamente
} 
Pero en verdad significativo parece que al primero, en 1589, a la hora de hablar de retórica y teología, no pudiera invocarse sin la mención al segundo. Era una suerte de obligación definitoria. En el tiempo de Sara, el sueño del humanismo así agotaba, ya notablemente desnaturalizado, su último aliento en los dominios hispanos de la Casa de Austria. Simón Abril y su diluida reivindicación - que ya podía incluso resultar atemporal- de una reforma retórica de la teología, constituían asi el episodio de cierre de un itinerario intelectual frente al cual, y en cualquiera de sus formulaciones, la teologizada cultura hispana demostraba ser plenamente impermeable. Inaugurado el momento suareciano sólo las Instructiones Praedicatoribus Verbi Dei tenian cabida, espacio y sentido en una Monarquía Católica fundada en religión, la única retórica al fin y al cabo compatible con una vida contemplativa y un Rey filósofo ${ }^{4 t}$.

$\therefore$ Cfr., SMith, H.D. Preaching in the Spanish Golden Age. Oxford, 1980. 